\title{
Physical and Chemo/Mechanical behaviors of fly ash and silica fume belite cement pastes- Part I
}

\author{
H.H.M. Darweesh ${ }^{\text {a, * }}$
}

a Refractories, Ceramics and Building Materials Department, National Research Centre, Cairo, Egypt.

*Corresponding author Email: hassandarweesh2000@yahoo.com

DOI: https://doi.org/10.34256/nnxt2121

Received: 20-05-2021; Revised: 01-06-2021; Accepted: 01-06-2021; Published: 02-06-2021

Abstract: Physical, chemical and mechanical properties of high belite cement (HBC) blended with high pulverized fly ash (HPFA) with stable ratio of silica fume (SF) in comparison with Portland cement (OPC) were investigated. Results showed that the water of consistency and setting times (Initial and final) tended to increase with the increase of HPFA content. The bulk density and compressive strength were also improved and enhanced with the increase of HPFS content at all hydration times, but only up to $15 \%$ HPFA, and then decreased with further increase. However, the total porosity slightly decreased, but started to increase with further increase of $>15 \%$ HPFA. The free lime content of the pure OPC and HBC gradually were increased as the hydration times progressed up to 90 days, while those of blended cements increased only up to 7 days and then decreased onward. The results were confirmed by measuring the heat of hydration and ultrasonic pulse velocity for the optimum cement pastes comparing with those of both OPC and HBC. The heat of hydration of the optimum cement pastes was decreased at all hydration times and become lower than those of OPC and HBC. The ultrasonic pulse velocity test (USPV) proved that the uniformity and quality of the matrix of the hardened cement pastes are good with no cracks.

Keywords: OPC, HBC, HPFA, SF, Setting, Density, Porosity, Strength, Free lime, Heat of hydration.

\section{Introduction}

\subsection{Scope of the problem}

Portland cements (PCs) are being the main product for the fabrication of mortars and concretes in the building industry $[1,2]$. In spite of its ubiquitous usage, PC is a quite environmentally contentious material, where a ton of Portland cement clinker released about $\sim 0.87$ tons of $\mathrm{CO}_{2}$ into the atmosphere [3], that produces from the decomposition and burning of limestone and fuel. This reduces into $~ 7 \%$ of the total anthropogenic $\mathrm{CO}_{2}$ emissions with $\mathrm{BCs}$ [4]. belite cements (BCs) mainly containing a high content of belite $\left(\beta-C_{2} S\right)$, but a lower contents of alite $\left(C_{3} S\right)$ and calcium aluminates $\left(\mathrm{C}_{3} \mathrm{~A}\right.$ or $\left.\mathrm{C}_{4} \mathrm{AF}\right)$, are currently used as low heat cements. These binders produce high amounts of $\mathrm{CSH}-$ gel and have very good durability properties [5-7], and some other advantages as a lower limestone level accompanied with lower associated $\mathrm{CO}_{2}$ emissions, a lower energy generation, a lower kiln operating temperature, i.e. a lower $\mathrm{CO}_{2}$ and $\mathrm{NO}_{x}$ emissions due to the burning of fuel and a lower temperature increase at early hydration age. However, early-age strength developments are not competitive with those of Portland cements.

The reduction of $\mathrm{CO}_{2}$ footprint of climate crisis $[1,5,8,9]$. The production of infrastructures with a longer service life $[10,11]$ would also contribute to the overall decrease of $\mathrm{CO}_{2}$ footprint, as less cement will be needed. This will reduce the production of concrete demolition waste in the future. For these endeavors, it will be needed more durable cements with a lower embodied carbon content, novel techniques to quantify short- and long-term hydration chemistry and microand meso-structure developments [12], and also original data correlation tools [13] for better predictions.

High belite cement (HBC) is widely employed as the main material in the construction of dams, canals and other water conservancy engineering structures to control the cracks that may be occurred due to high temperatures $[13,14]$. Previous research studies have thoroughly investigated the thermal and mechanical properties, crack resistance and deformation performance of HBC cement or concrete, which all proved that $\mathrm{HBC}$ is a cementitious material 
with ideal characteristics of a low hydration heat, a high long-term strength, energy saving and environmental protection for hydraulic concretes [1518]. Due to the influence on local environment and huge investment, the safety and durability for water conservancy engineering must be ensured over hundred years or even longer. It is one of the most significant long-term performances to be considered for the hydraulic cement structures.

The high belite cement (HBC) has a higher content of $\beta-C_{2} S$ and lower contents of alite $\left(C_{3} S\right)$ and celite $\left(C_{3} A\right)$. Accordingly, it is commonly expected that the leaching of $\mathrm{HBC}$ could be less intensive compared to OPC. In fact, the different mineral compositions lead to the distinctions of Calcium-Silicon ratio $(\mathrm{Ca} / \mathrm{Si}), \mathrm{CH}$ content, hydration product morphology and gypsum content notably. These are the key factors affecting the calcium leaching evolution of cement-based materials $[19,20]$.

In the following stages, the use of supplementary cementitious materials is undoubtedly the strategy with the lowest economic and performance impacts [1,8,21-23]. The typical supplementary cementitious materials used by the cement industry are industrial wastes as blast furnace slags, fly ashes and silica fume. The long term availability of the industrial wastes will accordingly decrease [21] as in case of fly ash in the United States and Europe. For instance, calcium sulfoaluminate cements or high belite-cements of alkaline activation $[7,24-26]$ are facing tremendous challenges worldwide. This is essentially contributed to practice codes, availability of raw materials and costs.

Only one way to reduce $\mathrm{CO}_{2}$ footprints, cements with the same components of $\mathrm{PC}$, but with lower limestone demand which is the belite cements
(BCs). These binders are mainly ettringite-based and focused on Ordinary Portland and active, CSH gelbased belite binders.

\subsection{Objectives of the study}

The essential target of the current investigation is to evaluate and follow the effect of fly ash (HPFA) in combination with a certain ratio of silica fume (SF) on the physical, chemical and mechanical properties of belite cement in comparison with OPC cement. The obtained results were confirmed measuring the heat of hydration and ultrasonic pulse velocity tests.

\section{Experimental Section}

\subsection{Raw materials}

The raw materials which were used in the present research study are Ordinary Portland cement (OPC Type I- CEM I 42,5R), High belite cement (HBC), high pulverized flay ash (HPFA) and silica fume (SF). The blaine surface areas of the four raw materials were $3400,3763,4150$ and $19230 \mathrm{~cm}^{2} / \mathrm{g}$, respectively. The blaine surface area was applied by the "Air Permeability Apparatus". The OPC and HBC samples were provided by the new cement factory, Sohag, Egypt, while HPFA sample was provided from a local plant, Giza, Egypt. The SF sample was supplied by the ferrosilicon alloys company, Edfo, Egypt. The chemical composition of the OPC, HBC, HPFA and SF samples that measured by $\mathrm{X}$-ray florescence technique (XRF) is shown in Table 1. The mineralogical phase composition of the used OPC and $\mathrm{HBC}$ as recieved from the factory is given in Table 2, while the mix composition is illustrated in Table 3.

Table 1. Chemical analysis of the raw materials, wt.\%.

\begin{tabular}{|l|l|l|l|l|l|l|l|l|l|l|l|}
\hline $\begin{array}{l}\text { Oxide } \\
\text { Materials }\end{array}$ & $\mathrm{SiO}_{2}$ & $\mathrm{Al}_{2} \mathrm{O}_{3}$ & $\mathrm{Fe}_{2} \mathrm{O}_{3}$ & $\mathrm{CaO}$ & $\mathrm{MgO}$ & $\mathrm{Na}_{2} \mathrm{O}$ & $\mathrm{K}_{2} \mathrm{O}$ & $\mathbf{S O}_{3}$ & $\begin{array}{l}\text { Insoluble } \\
\text { residue }\end{array}$ & LOI & Total, \% \\
\hline OPC & 20.41 & 5.51 & 3.64 & 61.53 & 1.60 & 1.01 & 1.16 & 2.07 & 1.63 & 1.44 & 100 \\
\hline $\mathrm{HBC}$ & 23.62 & 3.45 & 4.28 & 57.54 & 4.89 & 0.07 & 0.13 & 2.43 & 0.77 & 1.82 & 100 \\
\hline FA & 50.53 & 31.64 & 6.05 & 5.13 & 1.47 & 0.76 & 3.14 & 0.17 & 0.42 & 1.51 & 100 \\
\hline SF & 93.15 & 0.11 & 0.15 & 1.12 & 0.32 & 0.08 & 0.41 & 0.41 & ---- & 0.71 & 100 \\
\hline
\end{tabular}


Table 2. Mineralogical constituents of OPC and HBS cement samples, wt. \%.

\begin{tabular}{|l|l|l|l|l|}
\hline Phase Cement & $\mathbf{C}_{\mathbf{3}} \mathbf{S}$ & $\boldsymbol{\beta}_{-} \mathbf{C}_{\mathbf{2}} \mathbf{S}$ & $\mathbf{C}_{\mathbf{3}} \mathbf{A}$ & $\mathbf{C}_{\mathbf{4}} \mathbf{A F}$ \\
\hline OPC & 48.37 & 24.72 & 8.28 & 11.45 \\
\hline HBC & 29.12 & 42.87 & 2.03 & 12.57 \\
\hline
\end{tabular}

Table 3. Mix composition from the used raw materials, wt. \%.

\begin{tabular}{|l|l|l|l|l|}
\hline Materials Mixes & OPC & HBC & HPFA & SF \\
\hline P0 & 100 & ---- & ---- & ---- \\
\hline B0 & 100 & ---- & ---- & ---- \\
\hline B1 & ---- & 95 & 5 & ---- \\
\hline B2 & ---- & 90 & 5 & 5 \\
\hline B3 & ---- & 85 & 10 & 5 \\
\hline B4 & ---- & 80 & 15 & 5 \\
\hline B5 & ---- & 75 & 20 & 5 \\
\hline
\end{tabular}

\subsection{Preparation and methods}

There are five blended cement batches composed from Belite cement (BC), high pulverized fly ash (HPFA) and silica fume (SF). The belite cement batches were composed of BC, HPFA and SF as 100:0:0, 95:5:0, 90:5:5, 85:10:5, 80:15:5, and 75:20:5 having the symbols: B0, B1, B2, B3, B4 and B5, respectively (Table 3 ). The blending process of the various cement batches was firstly done in a porcelain ball mill using three balls for two hours to assure the complete homogeneity of all cement batches. The standard water of consistency and setting times $[5,6,27,28]$ of the various cement pastes were directly measured using Vicat Apparatus. The water of consistency could be calculated from the following relation:-

$$
\text { WC, } \%=A / C \times 100
$$

Where, $\mathrm{A}$ is the amount of water taken to produce a suitable paste, $\mathrm{C}$ is the amount of cement mix $(300 \mathrm{~g})$. During mixing, the correct predetermined w/c-ratio (water of consistency) was poured into the cement portion inside the mixer gradually. Then, the mixer was run for 5 minutes at an average speed of $10 \mathrm{rpm}$ in order to have perfect homogenous pastes. Before casting, the moulds were delt with a thin film of a motor engine oil to facilitate the release of the cement cubes from the moulds when the moulds were de-moulded. The cement pastes were then moulded into one inch cubic stainless steel moulds $(2.5 \times 2.5 \times$ $2.5 \mathrm{~cm}^{3}$ ) using about $500 \mathrm{~g}$ from the cement powder, vibrated manually for three minutes, and also on a mechanical vibrator for another three minutes to remove all air bubbles tapped inside the cement pastes. The moulds were filled to the top surface and smoothed with a flat stainless steel trowel or a suitable spatula to obtain a flat and smooth surface [29-32]. After casting of samples, they were covered with a wet sheet during the first 24 hours to prevent moisture loss. Hence, the moulds were kept in a humidity chamber for 24 hours under $95 \pm 1$ relative humidity $(\mathrm{RH})$, and room temperature $(23 \pm 1)$, demoulded in the next day and soon cured and totally immersed in water at an ambient laboratory temperature till the time of testing for heat of hydration, bulk density, apparent porosity, compressive strength, combined water and free lime contents at 1, 3, 7, 28 and 90 days. This is necessary for the cement cubes as it facilitates the proper hydration of cement phases.

The bulk density (BD) and total porosity $(\delta)$ of the hardened cement pastes [29-32] were calculated from the following equations:-

$$
\begin{aligned}
& \text { B.D, }\left(\mathrm{g} / \mathrm{cm}^{3}\right)=\mathrm{W} 1 /(\mathrm{W} 1-\mathrm{W} 2) \times 1 \\
& \delta, \%=(0.99 \times \mathrm{We} \times \mathrm{BD}) /(1+\mathrm{Wt})
\end{aligned}
$$

Where, 0.99 is the specific volume of free water, We is the free or evaporable water content, BD 
is the bulk density, $\mathrm{g} / \mathrm{cm} 3$ and $\mathrm{Wt}$ is the total water content which is equal to the sum of We and $\mathrm{Wn}$ contents, where $\mathrm{Wn}$ is the combined water. The compressive strength (CS) of the various hardened cement pastes [33-36] was measured and calculated from the following relation:-

$$
\begin{aligned}
& \mathrm{CS}=\mathrm{L}(\mathrm{KN}) / \mathrm{Sa} \quad\left(\mathrm{cm}^{2}\right) \quad \mathrm{KN} / \mathrm{m}^{2} \quad \mathrm{x} 102 \\
& \left(\mathrm{Kg} / \mathrm{cm}^{2}\right) / 10.2(\mathrm{MPa})
\end{aligned}
$$

Where, $L$ is the load taken, Sa is the surface area. Thereafter, about 10 grams of the broken specimens were first well ground, dried at $105^{\circ} \mathrm{C}$ for 30 $\mathrm{min}$. and then were placed in a solution mixture of $1: 1$ methanol: acetone to stop the hydration [37-40]. The free lime content (FLn) of the hydrated samples predried at $105^{\circ} \mathrm{C}$ for 24 hours was also determined. About $0.5 \mathrm{~g}$ sample $+40 \mathrm{ml}$ ethylene glycol $\rightarrow$ heating to about 20 minutes without boiling. About 1-2 drops of $\mathrm{pH}$ indicator were added to the filtrate and then titrated against freshly prepared $0.1 \mathrm{~N} \mathrm{HCl}$ until the pink color disappeared. The $0.1 \mathrm{~N} \mathrm{HCl}$ was prepared using the following equation:

$$
\mathrm{V} 1=\mathrm{N} \times \mathrm{V} 2 \times \mathrm{W} \times 100 / \mathrm{D} \times \mathrm{P} \times 1000
$$

Where, $\mathrm{V} 1$ is the volume of $\mathrm{HCl}$ concentration, $\mathrm{V} 2$ is the volume required, $\mathrm{N}$ is the normality required, $\mathrm{W}$ is the equivalent weight, $\mathrm{D}$ is the density of $\mathrm{HCl}$ concentration and $\mathrm{P}$ is the purity (\%). The heating and titration were repeated several times until the pink colour did not appear on heating. The free lime content [41-43] was calculated from the following relation:-
FLn, \% $=(\mathrm{V} \times 0.0033 / 1) \times 100$

Where, FLn and $\mathrm{V}$ are the free lime content and the volume of $0.1 \mathrm{~N} \mathrm{HCl}$ taken on titration, respectively.

The heat of hydration of the prepared blended cement pastes has been experimentally investigated to confirm the obtained results [44-46\}. Ultra-sonic pulse velocity (UPV) method (Figure 1) is one of the prominent non-destructive testing (NDT) methods. It is mainly carried out to assess the uniformity and relative quality of existing structures and specimens. The test was carried out on 1, 3, 7, 28 and 90 days.

The mineral composition of PFa specimen was investigated by X-ray diffraction patterns (XRD) and diffration thermal analysis (DTA). The XRD analysis was achieved by a Phillips X-ray diffractometer (XRD), PW 1710 powder with an anticathode copper radiation and Cu-Ka radiation, wavelength of $1.54178 \AA$ and a graphite monochromator. The tube working voltage was $40 \mathrm{kV}$ and current strength was $30 \mathrm{~mA}$, in the range $5-50^{\circ} 2 \theta$ with a step of 0.02 and 0.5 seconds retention time for each step. The DTA analysis was carried out using NETZSCH Geratobau Selb, Bestell-Nr. $348472 \mathrm{C}$ at a heating rate $10{ }^{\circ} \mathrm{C} / \mathrm{min}$ up to $1000{ }^{\circ} \mathrm{C}$. The SEM images of the fractured surfaces, coated with a thin layer of gold, were obtained by JEOL-JXA-840 electron analyzer at accelerating voltage of $30 \mathrm{KV}$.

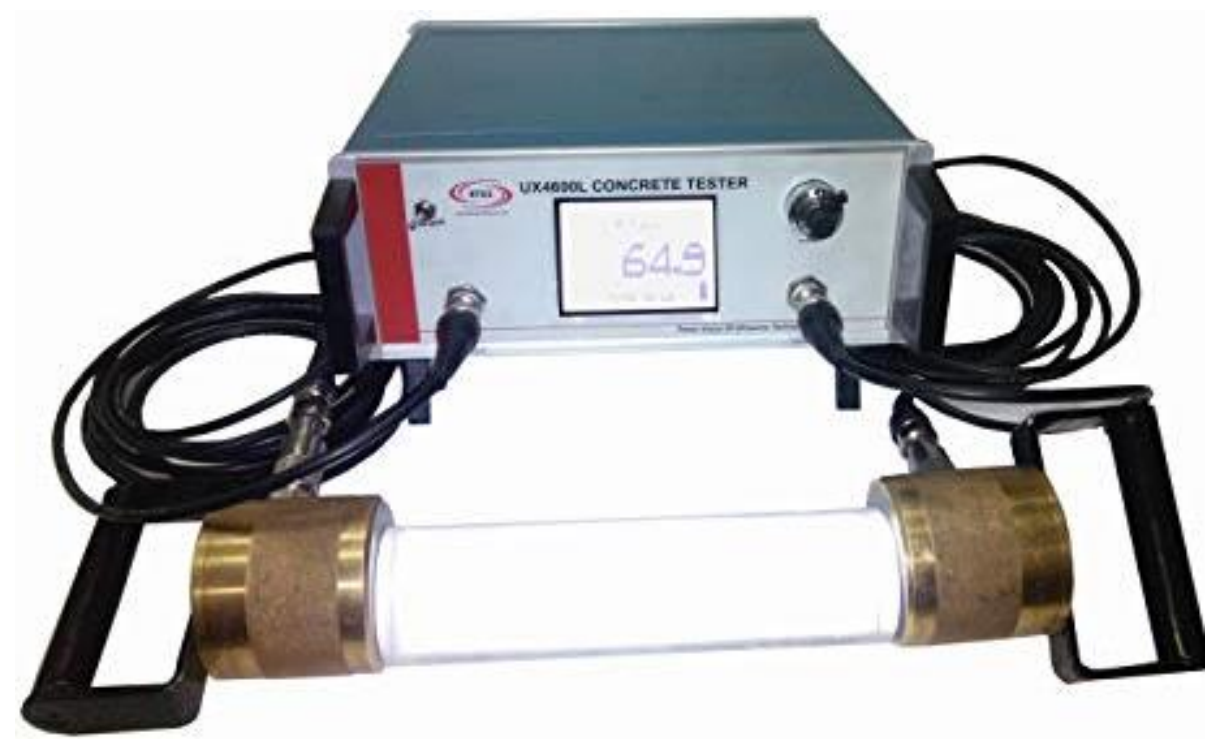

Figure 1. Ultrasonic Pulse Velocity Tester. 


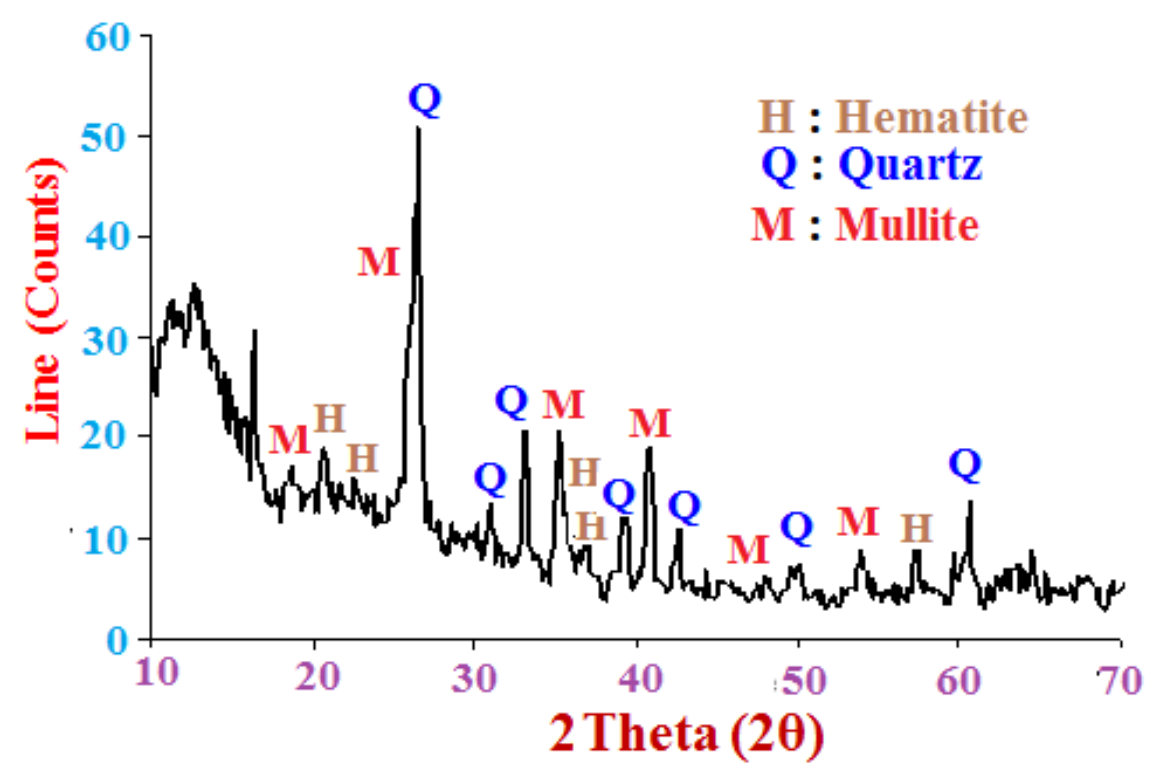

Figure 2. X-ray diffraction patterns of the used fly ash sample.

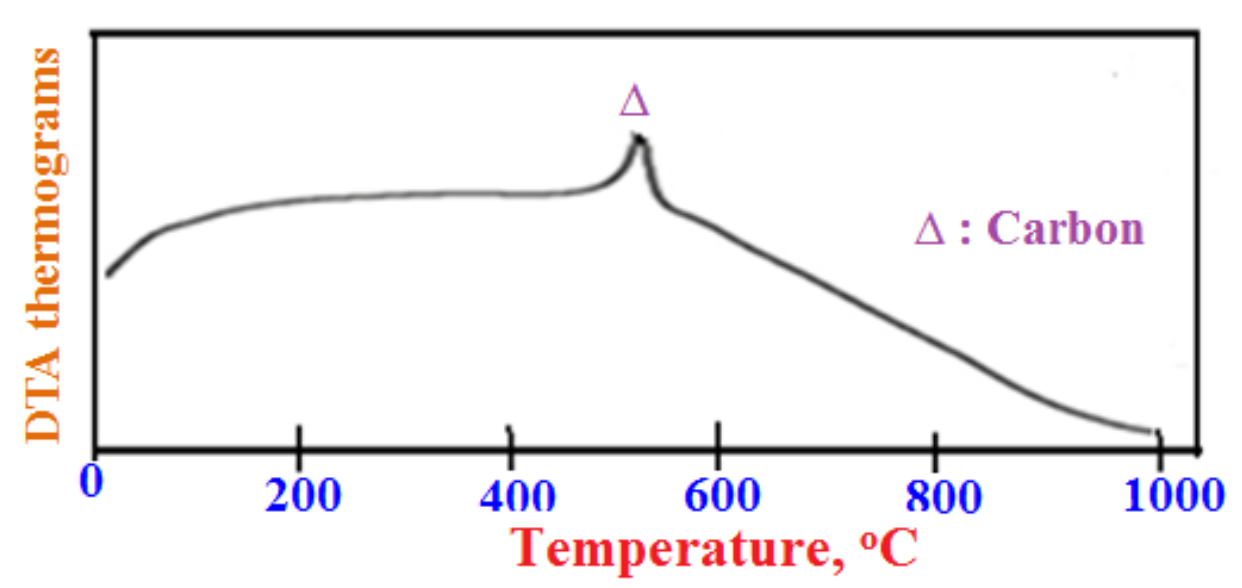

Figure 3. DTA analysis of the used fly ash sample.

\section{Results and Discussions}

\subsection{XRD, DTA analyses of HPFA}

The XRD diffraction patterns of the used fly ash sample are shown in Figure 2. Crystalline and amorphous phases are detected and also the differences in the amounts of amorphous phases. The crystalline phases were identified according to JCPDS standards. The content of any individual mineral phases cannot be easily identified. The FA sample contains a significant amount of amorphous matter but low amounts of crystalline phases, quartz (Q) and feldspar ( $F)$. In most cases, hematite $(H)$, anhydrite $(A)$ and mullite $(\mathrm{M})$ are detected. The amorphous phase minerals are more reactive if it is compared to the crystalline phases. This confirms the exploitation of FA as an alternative substitute for normal raw mixture used to produce Portland cement clinker.
The DTA thermograms of FA sample is shown in Figure 3. The exothermal peak at about $500-550{ }^{\circ} \mathrm{C}$ proves that carbon does not burned completely. The existence of unburned carbon in FA sample make it to be used successfully as a suitable raw material in the raw mixture but with smaller amounts of fuel. Hence, it is in turn lead to the reduction of the energy needed for the sintering process [47]. The DTA curve of the studied FA sample up to $1000{ }^{\circ} \mathrm{C}$ did not show any other exo- and/or endothermic peaks that could eventually correspond to the formation of new mineral phases during heating and/or sintering.

\subsection{SEM of BC and HPFA}

The SEM images of the used belite cement and HPFA is shown in Figure 4. The cement minerals are made of small particles $(<100 \mathrm{~nm})$. The grain size of 
the clinker was less than $2 \mu \mathrm{m}$. The smaller particle size, looser structure, higher porosity, and crystal structure of $\mathrm{C}_{12} \mathrm{~A}_{7}$ revealed that this clinker had higher hydration activity when compared with that calcined at a high temperature. In addition, unreacted mineral particles originating from the FA were observed. The porous particles increased the water requirement and hydration rate of the cement. The smaller grain sizes improved the grindability of all clinkers, which reduced the energy consumption in the cement grinding process, while there are several particulates in HPFA sample with various shapes and sizes as flocculants or almost globulars.

\subsection{Water of consistency}

The water of consistency (water/cement ratio) of belite cement pastes incorporating HPFY and SF comparing with those of Portland cement (OPC) were graphically represented in Figure 5 . The water of consistency of OPC pastes was $29 \%$, while that of bilite cement was $29.25 \%$, i.e. the water of consistency of belite cement was slightly higher than that of Portland cement [38-40]. This ratio was enhanced with the addition of both HPFA and SF. This is mainly attributed to that the addition of either PHFS or SF increased the blaine fineness of the cement batches. So, the water of consistency increased, in addition that the PHFA and/or SF like water [48-50].

On the other side, Figure 5 also shows the setting times (initial and final) of belite cement batches containing different ratios of HPFY and a constant ratio of SF (5 wt. \%) comparing with those of Portland cement. The setting times behaved as in case of water consistency, i.e. the setting times increased with gradual addition of HPFA and SF $[5,6,15$ $18,23,31,36,38,50]$. This is essentially due to the higher surface area caused by replacement of cement powder by HPFA and SF.

\subsection{Bulk density and total porosity}

The bulk density and total porosity of belite cement batches incorporating HPFY and a constant ratio of SF comparing with those of Portland cement pastes (OPC) were graphically represented in Figures 6 and 7, respectively. The bulk density of either Portland or Belite cements increased little by little with the addition of HPFA and SF, while the total porosity decreased. This was taken place at all curing times up till 90 days. This firstly is contributed to the normal hydration process of the major cement phases. Moreover, the addition of HPFA or SF further increased the bulk density and decreased the total porosity. This is due to the pozzolanic reactions that could be occurred between the constituents of these waste materials (HPFA and SF) with those of Portland or Belite cements [50-52].

During the hydration process or even the pozzolanic reactions, a large amount of hydration products could be formed, and soon deposited into the pore structure of the hardened cement pastes. This was leasing to the decrease of total porosity, which reflected positively on the bulk density, i.e. the bulk density was improved and enhanced $[5,6,23,36,40,44]$. This was continued up to B4 that was containing $15 \%$ HPFA and $5 \% \mathrm{SF}$, but then decreased with further addition of HPFA (B5), due to the deficiency of the main cementing and hydrating material $[5,6,44,52,53]$. Moreover, the bulk densities of the belite cement batches containing HPFA up to $15 \%$ were higer than those of the blank cement batches. Hence, the incorporation of HPFA into the belite cement activated the best hydration process [36-38,54]. Thereby, it was selected to be the optimum cement batch.

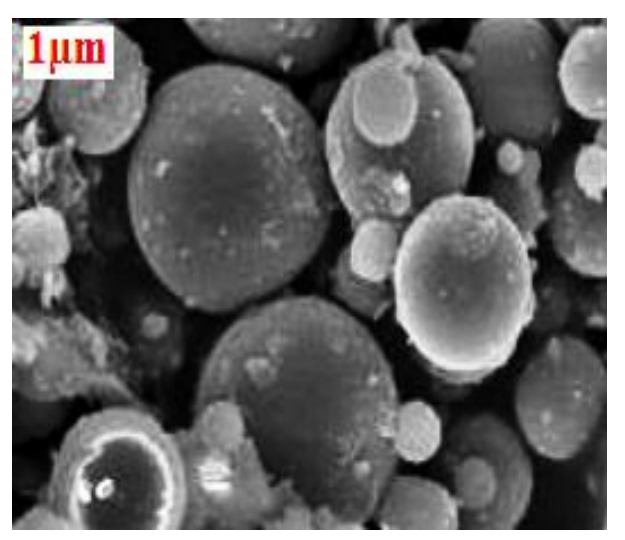

Figure 4. The SEM image of the used PFa sample 


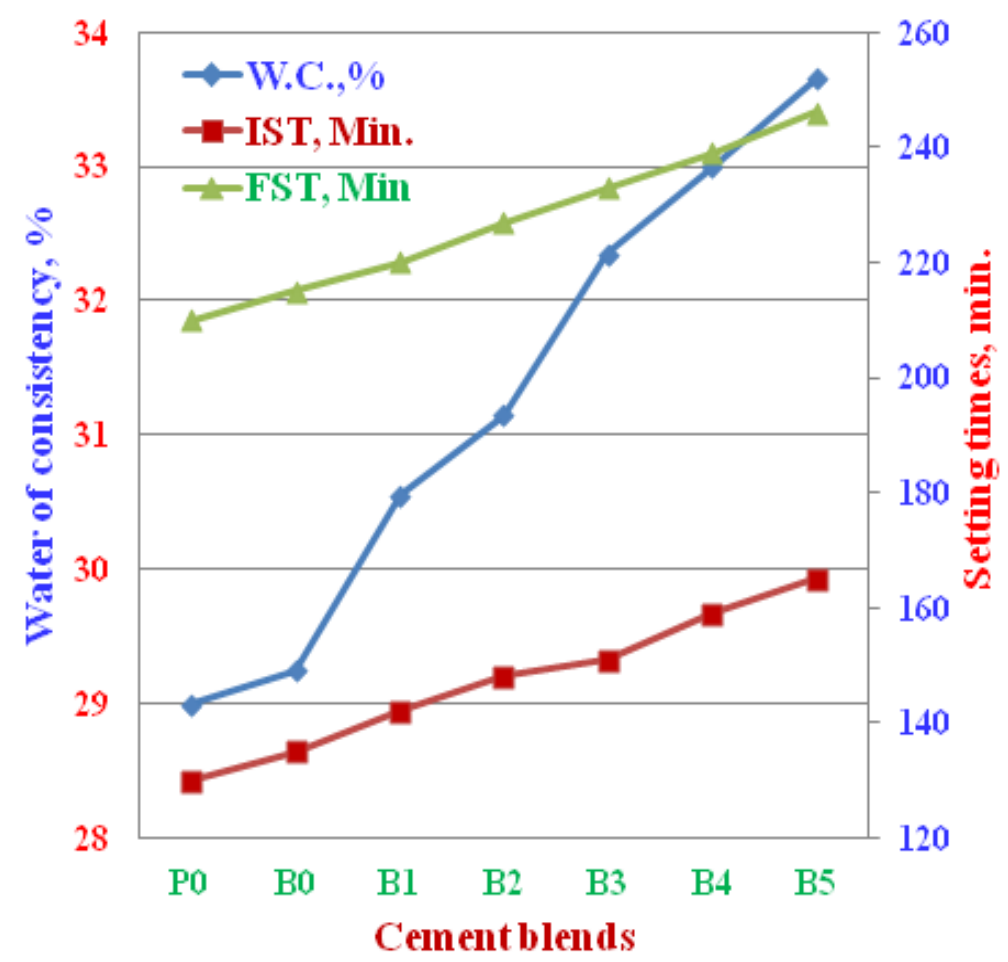

Figure 5. Water of consistency and setting times of the various blended cement pastes

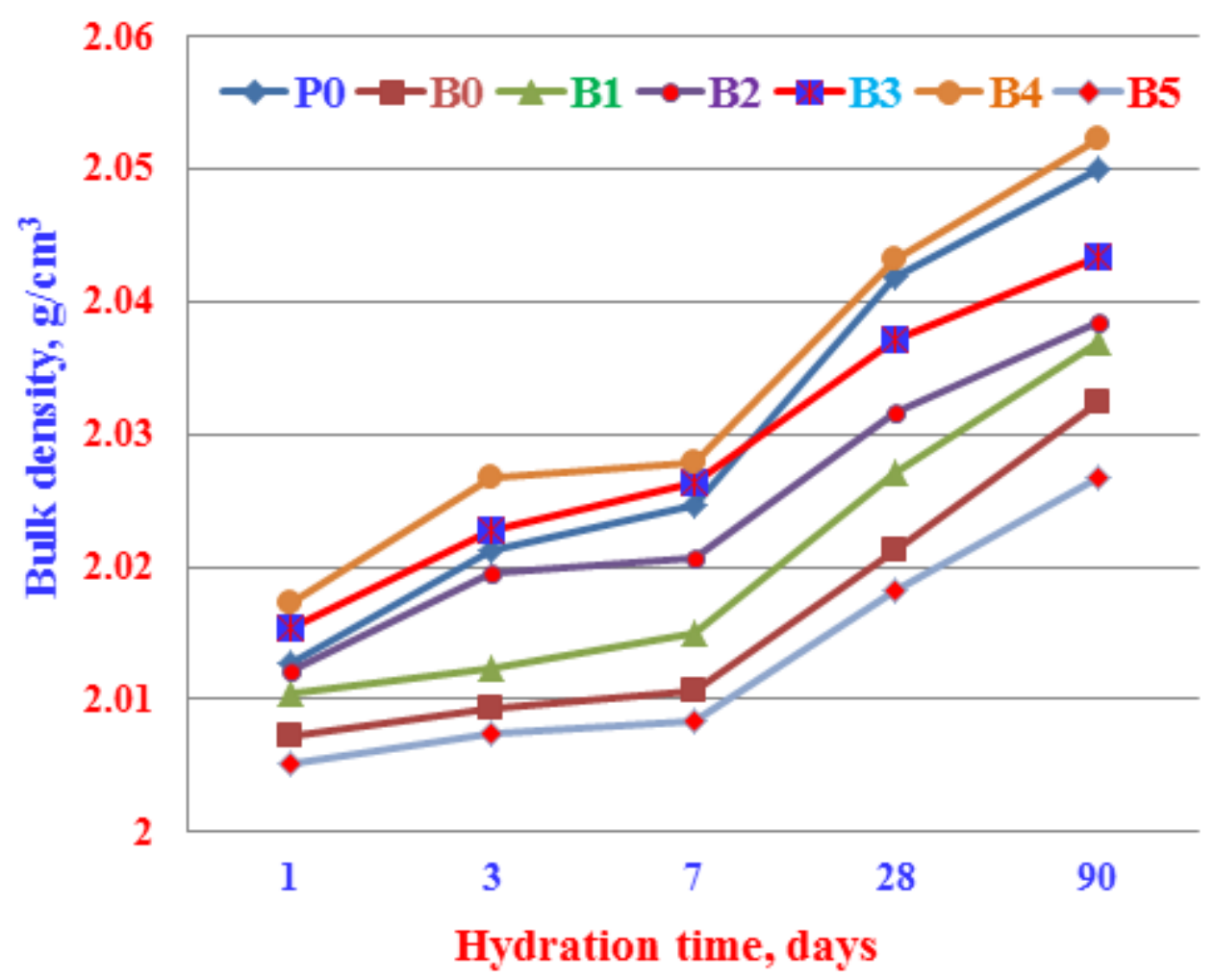

Figure 6. Bulk density of the various blended cement pastes hydrated up to 90 days. 


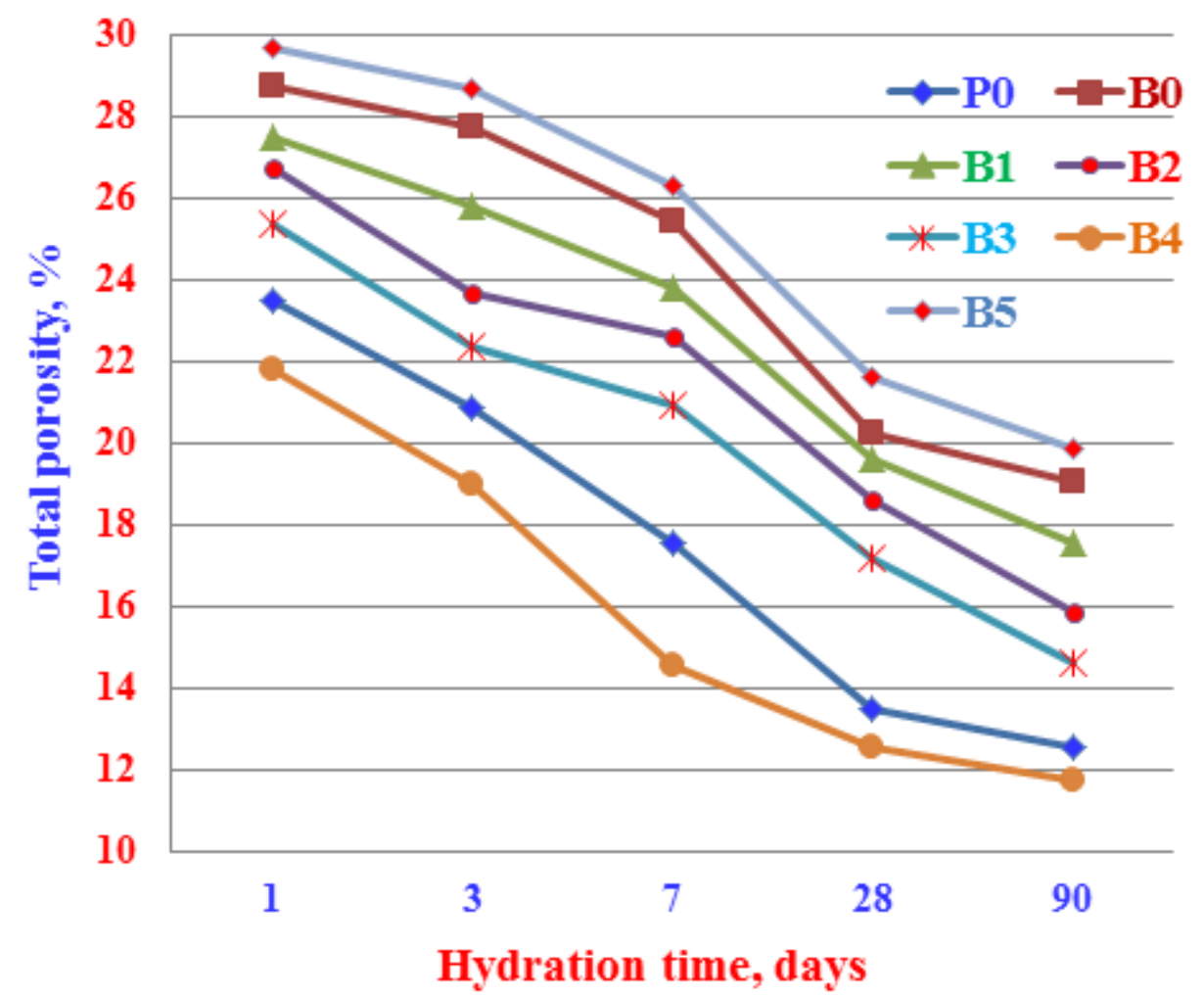

Figure 7. Total porosity of the various blended cement pastes hydrated up to 90 days.

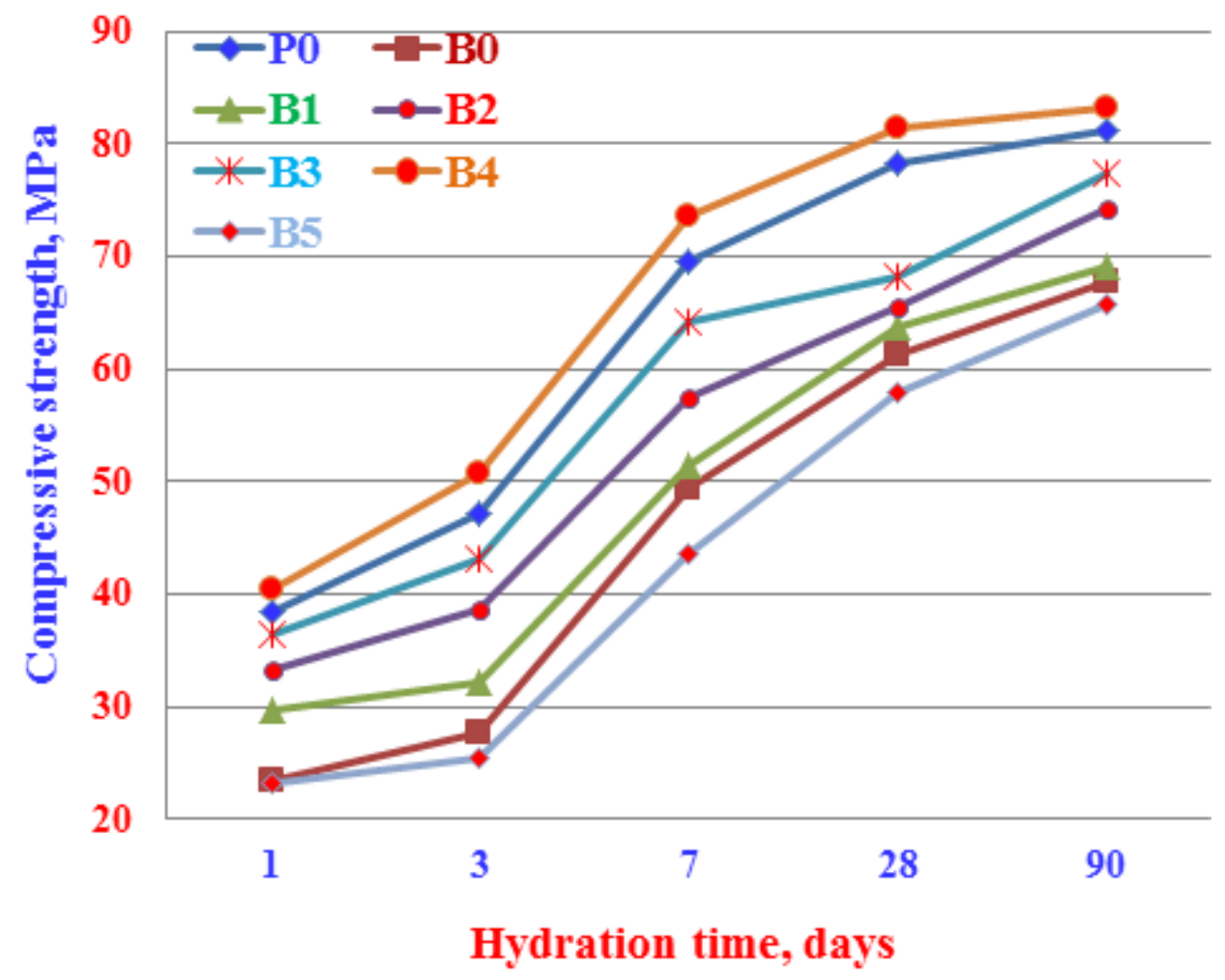

Figure 8. Compressive strength of the various blended cement pastes hydrated up to 90 days. 


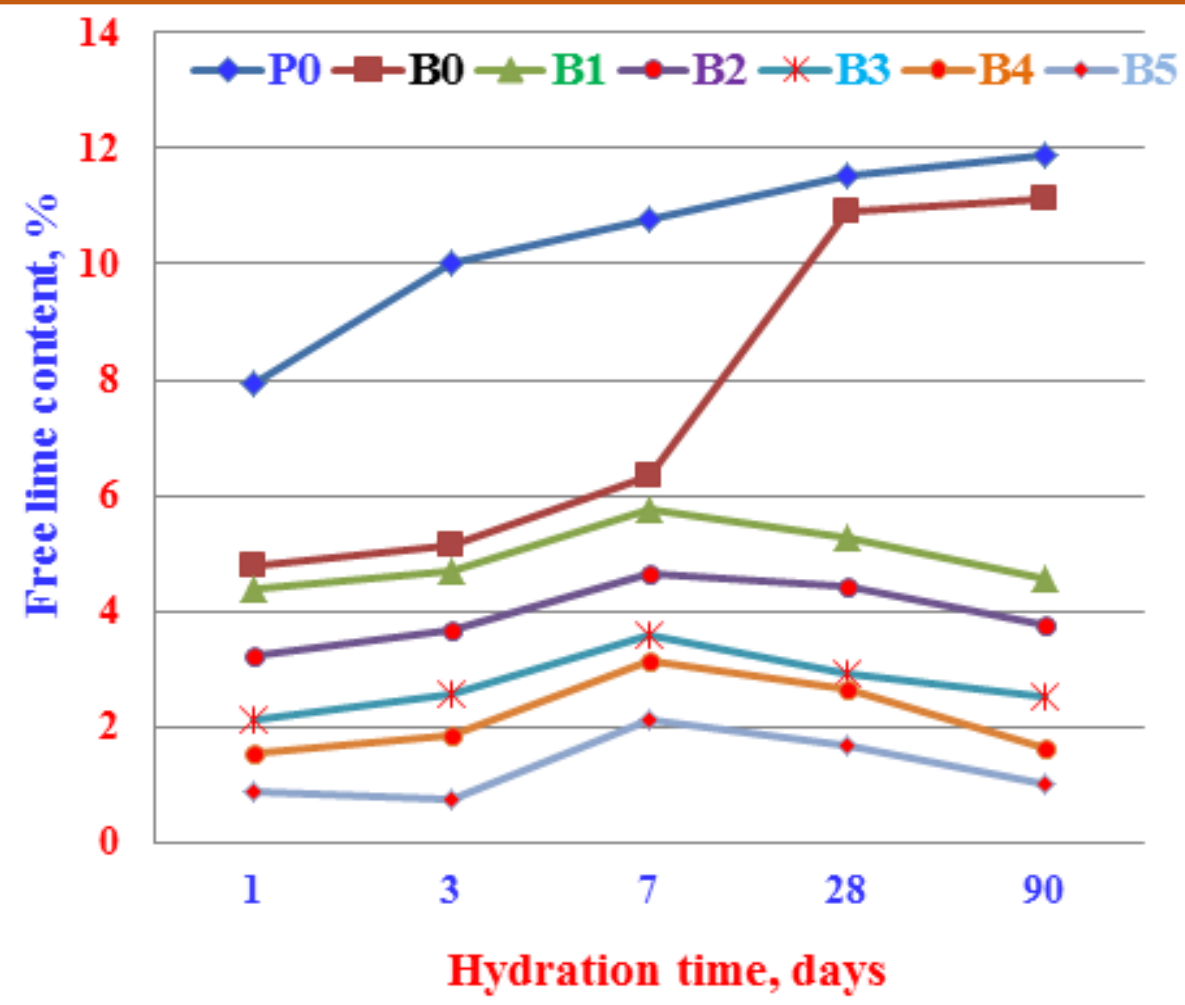

Figure 9. Free lime contents of the various blended cement pastes hydrated up to 90 days.

\subsection{Compressive strength}

The compressive strength of belite cement batches incorporating HPFY and a stable ratio of SF comparing with those of Portland cement (OPC) were graphically plotted in Figure 8 . It is obvious that the compressive strength of all cement pastes improved and enhanced with the hydration times up to 90 days. This is mainly contributed to the normal hydration process of all cement phases, particularly the silicate phases of the cement $\left(C_{3} S\right.$ and $\left.\beta-C_{2} S\right)$ [5,6,39,55-57]. The pozzolanic reactivity of HPFA and SF further improved and in turn increased the compressive strength much more than in case of its absence. So, the compressive strength of cement batches B1, B2, B3 and $\mathrm{B} 4$ were slightly higher than those of the blank (B0) at all hydration times. With cement batch B5 containing $20 \%$ HPFA, the compressive strength was adversely affected, i.e. it decreased and were becoming lower than those of the blank [55-58].

The increase of compressive strength is essentially attributed to the pozzolanic reactivity of HPFA and SF with the resulted free lime, $\mathrm{Ca}(\mathrm{OH})_{2}$ from the hydration of silicate phases of the cement forming hydration products that often deposited in the pore system of the hardened cement pastes. This would decrease the total porosity and increase the bulk density. This in turn would be reflected positively on the compressive strength, in addition to the filling action of the very fine HPFA and SF particles [59-61]. Furthermore, the compressive strength of the belite cement batch (B4) are higher than those the OPC pastes itself. Therefore, it was choice to be the optimum cement batch. The results of compressive strength are in good agreement with those of bulk density and total porosity.

\subsection{Free lime contents}

Generally, the hydration reaction of $\mathrm{C}_{3} \mathrm{~S}$ and $\beta$ $\mathrm{C}_{2} \mathrm{~S}$ in Portland cement (OPC) or belite cement (BC) can be expressed and simplified in the following relation:-

$$
\begin{aligned}
& 2 \mathrm{C}_{3} \mathrm{~S}+6 \mathrm{H}_{2} \mathrm{O}^{1 / 4} \rightarrow \mathrm{C}_{3} \mathrm{~S}_{2} \mathrm{H}_{3}+3 \mathrm{CH} \\
& 2 \mathrm{C}_{2} \mathrm{~S}+4 \mathrm{H}_{2} \mathrm{O}^{1 / 4} \rightarrow \mathrm{C}_{3} \mathrm{~S}_{2} \mathrm{H}_{3}+\mathrm{CH}
\end{aligned}
$$

Where, the amount of free lime, $\mathrm{CH}$ generated by $\beta-C_{2} S$ hydration is only one third of that produced by $C_{3} S[2,5,6]$. The free lime contents of the hydrated $\mathrm{OPC}$ and $\mathrm{BC}$ cements (PO and $\mathrm{BO}$ ) and the optimum belite cement pastes containing $15 \%$ HPFA and $5 \%$ SF (B4) is drawn versus the hydration ages up to 90 days in Figure 9. The free lime contents of OPC and BS cement pastes increased continuously as the hydration times progressed up to 90 days. This is evidently due to the normal hydration process of calcium silicate 
phases of the cement $[2,5,6,12,15,49,62]$. The free lime contents of OPC were higher at the early times of hydration up to 7 days than those of BC. In contrast, the free lime contents of OPC pastes were lower at older ages of hydration if compared with those of $\mathrm{BC}$. The free lime contents of belite blended cements increased only up to 7 days of hydration, and then started to decrease onward. This is mainly attributed to the pozzolanic abilities of both HPFS and SF with a part of the released free lime resulting from the hydration of silicate phases of both cements, which responsible for the decrease of free lime contents [16$18,23,31,36,38,42,50,52,63]$.

\subsection{Heat of hydration}

The heat of hydration of the pure OPC and Belite hardened cement pastes (PO and $\mathrm{BO}$ ) and the optimum belite cement pastes containing $15 \%$ HPFA and $5 \%$ SF (B4) is graphically plotted versus the hydration ages up to 90 days in Figure 10. As soon as the cement powders become in contact with water, a heat due to hydration was generally generated. The amount of the released heat increased as the hydration time progressed up to 90 days. The same trend was displayed by all cement pastes. This is mainly contributed to the continuous and gradual increase of the rate of hydration [5,6,63-66]. Furthermore, the rate of the generated heat of hydration was sharply enhanced at early ages up to 7 days. This is essentially attributed to the activation effect of the hydration reaction mechanism of $\mathrm{C}_{3} \mathrm{~S}$ by the very fine HPFA and SF particles. At later ages (28-90 days), the rate of hydration reaction was reduced, and therefore the evolved heat of hydration slightly increased. This may be due to the activation action mechanism of $\beta-C_{2} S$ by the fine HPFA and SF particles $[38,65,66]$. The heat of hydration of the OPC cement at later ages of hydration (28-90 says) seemed to be stable, while that of $B C$ increased more than that of OPC pastes. This was attributed to the fact that the hydration of The OPC phases started as soon as the cement powder became in contact with water, whereas in $\mathrm{BC}$ pastes it begins after 28 days of hydration $[5,6]$. The heat of hydration of the optimum cement pastes (B4) are the lowest, while that of the OPC pastes are the highest.

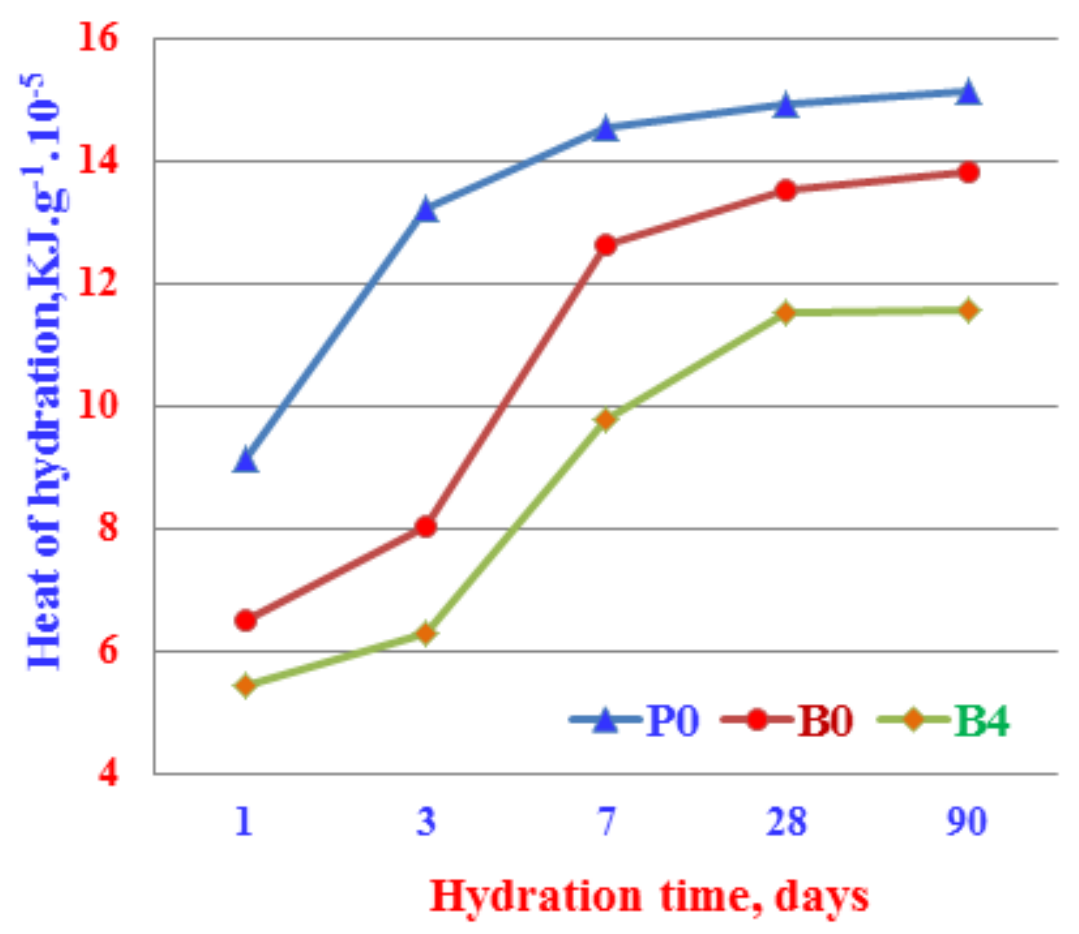

Figure 10. Heat of hydration of the pure OPC and Belite hardened cement pastes (PO and B0) and the optimum belite cement pastes (B4) 


\section{Conclusions}

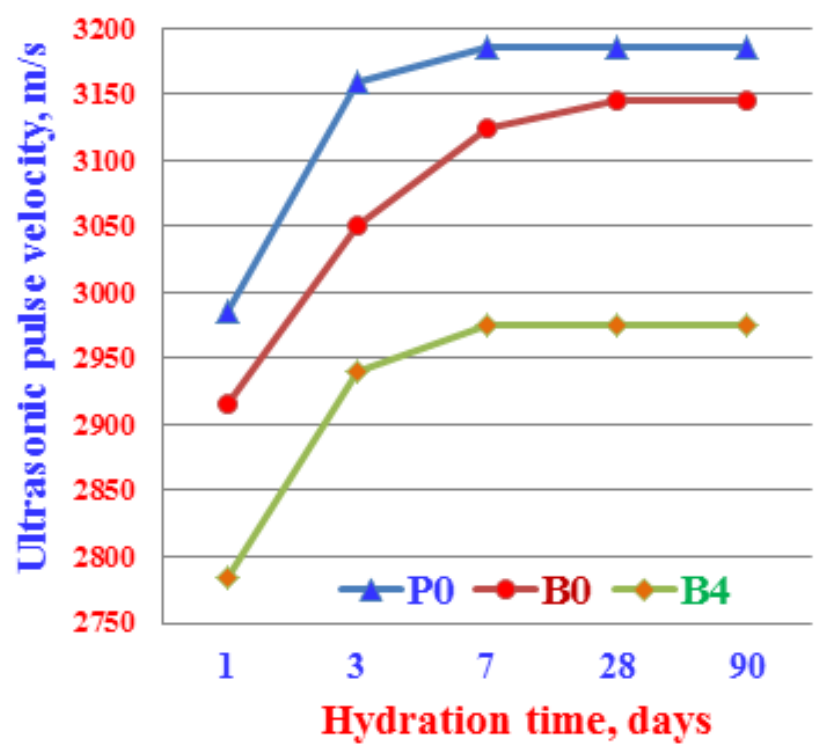

Figure 11. Ultrasonic pulse velocity (USPV) of the OPC and Belite hardened cements (PO and BO) as well as the optimum belite cement pastes (B4)

\subsection{Ultrasonic velocity test}

Ultra-sonic pulse velocity method (USPV) is mainly carried out to assess the uniformity and relative quality of structures and specimens. Hence, the ultrasonic pulse velocity (USPV) of the OPC (PO) and belite hardened cement (BO) as well as the optimum belite cement pastes containing $15 \%$ HPFA and $5 \%$ SF (B4) is graphically drawn versus the hydration ages up to 90 days in Figure 11. The USPV of the blank cements (OPC and B0) slightly increased only up to 7 days, and then seemed to be stable, i.e. the various constituents of blank cements (PO and B0) did not affect by the ultrasonic pulse velocity $[47,60]$. It is good mention that the same trend was displayed by cement pastes of the optimum batch (B4). Moreover, the values of USPV of B4 are the lowest, while those of $\mathrm{PO}$ are the highest. As a result, the USPV test proved that the matrix conformities of the cement pastes (B4) are well sticky and with good quality as the blank cements, i.e. good uniformity with no cracks [60]. The gradual increase of pozzolanic reactions of HPFA and SF with the evolved $\mathrm{Ca}(\mathrm{OH})_{2}$ resulting from the hydration of calcium silicate phases of the cement (Equations 1 and 2) is the main reason responsible for the high quality and uniformity of the cement matrix of B4 $[36,60]$. So, it was selected as the optimum one.
The water of consistency of the blank PO and B0 was 29 and $29.25 \%$, its initial and final setting times were 130, 210 minutes and 235, 215, respectively. These values tended to increase with the increase of HPFA content due to the too high level of fineness of both HPFA and SF, in addition to the high atmospheric temperature during the test. As soon as the cement powder becomes in contact with water, the total porosity was the highest and immediately started to decrease gradually with hydration time, while the bulk density increased due to the activating and filler effects of the active nano silica of the HPFA and SF, besides the pozzolanic action of these waste materials with the released free lime from the hydration process of calcium silicate phases of the cements. This was continued up till $15 \%$ HPFA and $5 \%$ SF (B4). This trend of behavior was reflected negatively with further increase of HPFA content (B5). The same trend was displayed by the compressive strength. The addition of $15 \%$ HPFA with 5\% SF (B4) to belite cement could be successfully applied without any adverse effects on the physical, chemical, mechanical and durable properties of the cement. Therefore, it was selected to be the optimum batch. The free lime content of the blank OPC and $\mathrm{BC}$ cements (PO and $\mathrm{BO}$ ) gradually increased as the hydration time progressed up to 90 days, while the free lime contents of all blended cement pastes containing different ratios of HPFA (B0-B5) increased only up to 7 days and then suddenly decreased. The heat of hydration of the optimum belite/Fly ash cement batch (B4) was lower than those of the belite cement control (B0) at all hydration times. This means that the belite blended cement release a lower rate of heat of hydration. The USPV test demonstrated that B4 assess the best conformity of the matrix. Moreover, all the obtained results are in a good agreement with each other.

\section{References}

[1] UN Environment, K.L. Scrivener, V.M. John, E. Gartner, Eco-efficient cements: potential, economically viable solutions for a low- $\mathrm{CO}_{2}$, cement-based materials industry, Cem. Concr. Res. 114, (2018) 2-26. [DOI]

[2] L. Wang, H.Q. Yang, S.H. Zhou, E. Chen, S.W. Tang, Mechanical properties, long-term hydration heat, shinkage behavior and crack resistance of dam concrete designed with low heat Portland (LHP) cement and fly ash, Construction and Building Materials, 187(2018) 
1073-1091. [DOI]

[3] P. Renforth, The negative emission potential of alkaline materials, Nature Communications, 10 (2019) 1401 [DOI]

[4] L. Barcelo, J. Kline, G. Walenta, E.Gartner, Cement and carbon emissions, Materials and Structures, 47(2014) 1055-1065. [DOI]

[5] A.M. Neville, (2011), Properties of Concrete, $5^{\text {th }}$ Edition, Longman Essex, UK.

[6] P.C. Hewlett, M. Liska, (2017), Lea's Chemistry of Cement and Concrete, $5^{\text {th }}$ Edition, Edward Arnold Ltd., London, UK.

[7] C. Shi, B. Qu, J.L. Provis, Recent progress in low-carbon binders, Cement and Concrete Research, 122(2019) 227-250. [DOI]

[8] M. Schneider, The cement industry on the way to a low-carbon future, Cement and Concrete Research, 124(2019) 105792. [DOI]

[9] P.J.M. Monteiro, S.A. Miller, A. Horvath, (2017) Towards sustainable concrete, Nature Materials, 16, 698-699. [DOI]

[10] M. Alexander, H. Beushausen, Durability, service life prediction, and modelling for reinforced concrete structures - review and critique, Cement and Concrete Research, 122 (2019) 17-29 [DOI]

[11] M.A.G. Aranda, Recent studies of cements and concretes by synchrotron radiation crystallographic and cognate methods, Crystallography Reviews, 22 (2016) 50-196 [DOI]

[12] J.W. Bullard, E.J. Garboczi, P.E. Stutzman, P. Feng, A.S. Brand, L. Perry, J. Hagedorn, W. Griffin, J.E. Terrill, Measurement and modeling needs for microstructure and reactivity of nextgeneration concrete binders, Cement and Concrete Composites, 101(2019) 24-31. [DOI]

[13] A. Cuesta, A. Ayuela, M.A.G. Aranda, Belite cements and their activation, Cement and Concrete Research, 140(2021) 106319. [DOI]

[14] R.D. Hooton, Future directions for design, specification, testing, and construction of durable concrete structures, Cement and Concrete Research, 124(2019) 105827. [DOI]

[15] K. Mori, T. Fukunaga, M. Sugiyama, K. Iwase, K. Oishi, O. Yamamuro, Hydration properties and compressive strength development of Low
Heat Cement, Journal of Physics and Chemistry of Solids, 73(2012) 1274-1277. [DOI]

[16] T. Staněk, P. Sulovský, Active low-energy belite cement, Cement and Concrete Research, 68(2015) 203-210. [DOI]

[17] L. Wang, H.Q. Yang, Y. Dong, E. Chen, S.W. Tang, Environmental evaluation, hydration and performance of low heat Portland (LHP) cement-based materials, Journal of Cleaner Production, 203 (2018) 540-558. [DOI]

[18] J. Gong, C. Jiang, X. Tang, Z. Zheng, L. Yang, Optimization of mixture proportions in ternary low-heat Portland cement-based cementitious systems with mortar blends based on projection pursuit regression, Construction and Building Materials, 238(2020) 117666. [DOI]

[19] E. Rozière, A. Loukili, Performance-based assessment of concrete resistance to leaching, Cement and Concrete Composites, 33(2011) 451-456. [DOI]

[20] C. Jiang, L. Jiang, X. Tang, J. Gong, H. Chu, Impact of calcium leaching on mechanical and physical behaviors of high belite cement pastes, Construction and Building Materials, 286(2021) 122983. [DOI]

[21] M.C.G. Juenger, R. Siddique, Recent advances in understanding the role of supplementary cementitious materials in concrete, Cement and Concrete Research, 78(2015) 71-80 [DOI]

[22] M.C.G. Juenger, R. Snellings, S.A. Bernal, Supplementary cementitious materials: new sources, characterization, and performance insights, Cement and Concrete Research, 122(2019) 257-273 [DOI]

[23] J. Skibsted, R. Snellings, Reactivity of supplementary cementitious materials (SCMs) in cement blends, Cement and Concrete Research, 124(2019) 105799. [DOI]

[24] E. Gartner, H. Hirao, A review of alternative approaches to the reduction of $\mathrm{CO}_{2}$ emissions associated with the manufacture of the binder phase in concrete, Cement and Concrete Research, 78(2015) 126-142 [DOI]

[25] J.L. Provis; A. Palomo, Advances in understanding alkali-activated materials, Cement and Concrete Research, 78(2015) 110-125. [DOI]

[26] M. Ben Haha, F. Winnefeld, A. Pisch, Advances 
in understanding ye'elimite-rich cements, Cement and Concrete Research, 123(2019) 105778. [DOI]

[27] ASTM-C187-86, Standard Test Method for Normal Consistency of hydraulic Cement, (1993) 148-150.

[28] ASTM-C191-92, Standard Test Method for Setting Time of Hydraulic Cement, (1993) 866868.

[29] H.H.M. Darweesh, Metakaolin Blended Cement Pastes, International Journal of Innovative Studies in Sciences and Engineering Technology, 6(2020) 5-18

[30] S.A.E. Aleem, M. Heikal, W.M. Morsi, Hydration characteristic, thermal expansion and microstructure of cement containing nanosilica, Construction and Building Materials, 59(2015) 151-160. [DOI]

[31] H.H.M. Darweesh, M.R. Abo-El-Suoud, Quaternary Cement Composites Containing Some Industrial By-products to Avoid the Environmental Pollution, EC Chemistry, 2(2015) 78-91.

[32] H.H.M. Darweesh, Mortar Composites Based on Industrial Wastes, International Journal of Materials Lifetime, 3(2017) 1-8.

[33] ASTM- C170-90, Standard Test Method for Compressive Strength of Dimension Stone, (1993) 828-830.

[34] ASTM-C109M, Standard Test Method for Compressive Strength of Hydraulic Cement Mortars (Using 2-in. Or [50-mm] Cube Specimens), Annual Book of ASTM Standards, ASTM International, (2013) West Conshohocken, PA.

[35] ASTM C39, Standard Test Method for Compressive Strength of Cylindrical Concrete Specimens. ASTM International, (2016) West Conshohocken, USA.

[36] H.H.M. Darweesh, Geopolymer cements from slag, fly ash and silica fume activated with sodium hydroxide and water glass, Interceram - International Ceramic Review, 6(2017) 226231. [DOI]

[37] S. Rukzon, P. Chindaprasirt, Utilization of bagasse ash in high-strength concrete, Materials \& Design, 34(2012) 45-50.
[38] H.H.M. Darweesh, Characteristics of Portland Cement Pastes Blended with Silica Nanoparticles, To Chemistry, 5(2020) 1-14.

[39] H.H.M. Darweesh, M.R. Abo El-Suoud, (2019) Influence of sugarcane bagasse ash substitution on Portland cement characteristics, Indian Journal of Engineering, 16, 252-266.

[40] A.N. Givi, S.A. Rashid, F.N.A. Aziz, M.A.M. Salleh, Experimental investigation of the size effects of $\mathrm{SiO}_{2}$ nano-particles on the mechanical properties of binary blended concrete, Composites Part B: Engineering, 41(2010) 673-677. [DOI]

[41] H Binici, E. Ortlek, Engineering properties of concrete made with cholemanite, barite, corn stalk, wheat straw and sunflower stalk ash, European Journal of Engineering and Technology, 3(2015) 23-34.

[42] W.J. Fan, X.Y. Wang, K.P. Park, (2015) Evaluation of the Chemical and Mechanical Properties of Hardening High Calcium Fly Ash Blended Concrete, Materials, 8, 5933-5952. [DOI]

[43] H.H.M. Darweesh; M.R. Abo El-Suoud, Saw dust ash substitution for cement pastes-Part I, American Journal of Applied Scientific Research, 2(2017) 1-9. [DOI]

[44] ASTM- Standards C186-80, (1980) Standard Test Method for Heat of Hydration of Hydraulic Cement.

[45] M. Elmaghraby, H.S. Mekky, M.A. Serry, Light weight insulating concrete based on natural pumice aggregate, InterCeram: International Ceramic Review, 61(2012) 354-357.

[46] T.D. Garrett, H.E. Cardenas, J.G. Lynam, Sugarcane bagasse and rice husk ash pozzolans: Cement strength and corrosion effects when using saltwater, Current Research in Green and Sustainable Chemistry 1-2(2020) 7-13. [DOI]

[47] Z. Giergiczny, Fly ash and slag, Cement and Concrete Research, 124(2019) 105826. [DOI]

[48] L. Kacimi, A. Simon-Masseron, S. Salem, A. Ghomari, Z. Derriche, Synthesis of belite cement clinker of high hydraulic reactivity, Cement and Concrete Research 39(2009) 559565 [DOI]

[49] J.W. Bullard, H.M. Jennings, R.A. Livingston, A. 
Nonat, G.W. Scherer, G.S. Schweitzer, K.L. Scrivener, J.J. Thomas, Mechanisms of cement hydration, Cem. Concr. Res. 41(2011) 12081223. [DOI]

[50] K. Mori, T. Fukunaga, M. Sugiyama, K. Iwase, K. Oishi, O. Yamamuro, Hydration properties and compressive strength development of Low Heat Cement, Journal of Physics and Chemistry of Solids, 73(2012) 1274-1277. [DOI]

[51] P. Nath, P.K. Sarker, Effect of GGBFS on setting, workability and early strength properties of fly ash geopolymer concrete cured in ambient condition, Construction and Building Materials, 66(2014) 163-171. [DOI]

[52] T.L. Avalos-Rend'on, E.A.P. Chelala, C.J. Mendoza Escobedo, I.A. Figueroa, V.H. Lara, L.M. Palacios-Romero, Synthesis of belite cements at low temperature from silica fume and natural commercial zeolite, Materials Science and Engineering: B, 229(2018) 79-85. [DOI]

[53] M. Boh'ǎc, T. Staňek, A. Zezulov'a, A. Rybov'a, D. Kub'atov'a, R. Novotný, Early hydration of activated belite-rich cement, Advanced Materials Research, 1151(2019) 2327. [DOI]

[54] T. Yang, H. Zhu, Z. Zhang, Influence of fly ash on the pore structure and shrinkage characteristics of metakaolin-based geopolymer pastes and mortars, Construction and Building Materials, 153(2017) 284-293. [DOI]

[55] T Sui, L. Fan, Z. Wen, J. Wang, Z. Zhang, Study on the properties of high strength concrete using high belite cement, Journal of Advanced Concrete Technology, 2(2004) 201206. [DOI]

[56] M.A. Bouzidi, A. Tahakourt, N. Bouzidi, D. Merabet, Synthesis and characterization of belite cement with high hydraulic reactivity and low environmental impact, Arabian Journal for Science and Engineering, 39(2014) 8659-8668. [DOI]

[57] T. Sui, L. Fang, Z .Wen, J. Wang, Properties of belite-rich Portland cement and concrete in China, J. Civ. Eng. Archit. 9(2015) 384-392. [DOI]

[58] J. Li, G. Geng, W. Zhang, Y.S. Yu, D.A. Shapiro, P.J.M. Monteiro, The hydration of $\beta$ - and $a^{\prime} \quad H$-dicalcium silicates: an X-ray spectromicroscopic study, ACS Sustainable Chemistry \& Engineering, 7(2019) 2316-2326. [DOI]

[59] V.M. John, B.L. Damineli, M. Quattrone, R.G. Pileggi, (2018), Fillers in cementitious materials - experience, recent advances and future potential, Cement and Concrete Research, 114, 65-78. [DOI]

[60] V. Balagopal, T.S. Viswanathan, Evaluation of Mechanical and Durability Performance of Coir Pith Ash Blended Cement Concrete, Civil Engineering and Architecture, 8(2020) 10281038.

[61] H.H.M. Darweesh, E.A. El-Anwar, H.S. Mekky, Addition of Limestone at the Expense of Gypsum in Portland Cement, Interceram International Ceramic Review, 67(2018) 18-27. [DOI]

[62] M. Saedi, K. Behfarnia, H. Soltanian, The effect of the blaine fineness on the mechanical properties of the alkali-activated slag cement, Journal of Building Engineering, 26(2019) 100897. [DOI]

[63] J. Yang, J. Huang, Y. Su, X. He, H. Tan, W. Yang, B. Strnadel, Eco-friendly treatment of low-calcium coal fly ash for high pozzolanic reactivity: A step towards waste utilization in sustainable building material, Journal of Cleaner Production, 238(2019) 117962. [DOI]

[64] H.H.M. Darweesh, Utilization of Perlite Rock in Blended Cement-Part I: Physicomechanical properties, Direct Research Journal of Chemistry and Material Sciences, 2(2014) 1-12.

[65] A. Echart, H.M. Ludwig, J. Stark, Hydration of the four main Portland cement clinker phases, Zement-Kalk-Gips, 48(1995) 443-452.

[66] R. Siddique, Properties of self-compacting concrete containing class F fly ash, Materials \& Design, 32(2011) 1501-1507. [DOI]

\section{Acknowledgement}

The author wishes to express their deep thanks to National Research Centre for helping to obtain materials, processing, preparing, molding and measuring all of the obtained data of the study, and moreover for financial assistance. 


\section{Funding}

No funding was received for conducting this study.

\section{Does this article screened for similarity?}

Yes

\section{Conflict of interest}

The Author has no conflicts of interest to declare that they are relevant to the content of this article.

\section{About the License}

(C) The author 2021. The text of this article is open access and licensed under a Creative Commons Attribution 4.0 International License 